\title{
Elderly, vulnerable and forgotten
}

At the time of writing, around 50\% of people over the age of 60 in South Africa had registered for COVID-19 vaccination on the government Electronic Vaccination Data System (EVDS). Of these, around 30\% have now been vaccinated. ${ }^{[1]}$ My husband and I, both over 60, registered the day before the EVDS officially opened for registration and received our confirmatory SMS. The process was pretty simple, but we are highly computer literate, English speaking and highly educated. First point. Around 10 days later we also registered with our medical aid. We, like all of us eligible for vaccination in the first phase of the official vaccine roll-out, were told that we should patiently wait for another SMS to give us an appointment. I did hear that friends in Cape Town started simply walking in to vaccine sites early in the process and received their vaccinations, but we live in the Garden Route, where vaccine sites didn't open for about a month after they started in the cities. Second point. We sat and patiently (well not so patiently) waited for our SMS to give us an appointment, expecting that as soon as vaccine sites started to open in our area these would arrive. They never did. Third point. Finally, some 6 weeks after registering with the EVDS, we started trying to walk in. Our first attempt was at a private site in George, on a Friday, my reasoning being that if there were vaccines left over they would want to use them. They had run out of vaccines the day before and didn't expect any more for about 10 days, but we could, along with 300 other people, put our names down on a list to be called if vaccines were available after those with appointments had been dealt with. A week later, I heard a very elderly man in our local pharmacy tell the pharmacist that he had just had his jab, at the TB hospital in George, as a walk-in. I rushed home and we drove through to George, to find that they were closed for the day and be told to come back at 7 am the next morning. Which we did, along with many, many other people over 60 who also did not have appointments, some from as far afield as Oudtshoorn. We were all vaccinated, helped by pleasant and patient staff, who dealt with a system that was clearly dysfunctional calmly and cheerfully. This all took three relatively long return journeys from our home, in our private car. Fourth point.

On 1 July 2021, registration opened for the over-50s, in spite of the fact that there are still likely to be around $70-80 \%$ of over- 60 s unvaccinated. Vaccinations are only supposed to start for this age group on 15 July. However, I know that many middle-class people aged between 50 and 59, most of whom are in the cities, have already started to get vaccines as walk-ins - excellent news, the more who are vaccinated the better. Irritatingly, though, they are all patting themselves on the back and saying how much better the uptake has been by their age group, and 'good for us'. Far more importantly, I cynically suspect that the reason government has opened vaccination up to the over-50s this early is to boost vaccine numbers, so that they can deflect further criticism of their appallingly badly mismanaged vaccine roll-out.

My point is that we need to look hard and urgently at what went wrong with the first phase of the roll-out, which was supposed to provide protection for the most vulnerable portion of our population. I would be willing to bet that the $30 \%$ of over- 60 s who have received their first dose of the vaccine are middle class, computer literate and have their own transport. Only $50 \%$ of those eligible have managed to navigate the EVDS, a complex, technology-centric system that fails in its most important function - to provide appointments to everyone who has registered. I would also be willing to bet that the $20 \%$ or so of those who registered who have not yet been vaccinated are still waiting patiently for appointments that never arrived, or received appointments at places that are too far from their homes, or received appointments so close to the time of the appointment that they could not manage to get to the designated place. Reports from the Eastern Cape suggest that there are many people who have to travel vast distances, at their own expense, to vaccine sites. ${ }^{[2]}$ Potential reasons for people in this age group not registering should be obvious, but clearly are not to government, who are blaming 'vaccine hesitancy', countered effectively by the University of Johannesburg and Human Sciences Research Council survey which showed that the level of acceptance of vaccines increased with age. ${ }^{[1]}$ This same survey showed that among people over 60 , only $63 \%$ of households had at least one member with internet access, and of course, most of these people do not have English as their home language.

There is currently a huge disparity in levels of vaccination among poorer people and the middle classes. ${ }^{[1]}$ Rather than addressing this to raise the overall levels of vaccination across the country, government has chosen to open vaccination up to groups who are easier to access (the 50 - 59 age group, teachers, police, SANDF and prisoners). There is already a disparity between vaccination rates in those who are insured (48\%) and those who are not (26\%). ${ }^{[1]}$ This disparity is likely to be seen again after the initial rush of registration and uptake by the over-50s. Those who have rushed to register and risk walk-ins at vaccine sites are probably also middle class and computer literate. This group have also watched the mess of the first phase when so few people received appointments. It will be interesting to see whether similar discrepancies start to arise down the line, once the middle classes in this age group have been vaccinated, compounded by the lack of vaccine sites at weekends in an age group who are more likely to be working and unable to take time off during the week.

In the meantime, there is a large body of elderly and vulnerable people who are not vaccinated. Without serious government will and highly targeted interventions, including providing transport to vaccine sites, scrapping the requirement for pre-registration, and the community engagement campaigns that are so conspicuous by their absence, these people will simply be forgotten. The more people who are vaccinated, the better it is for all of us. But we must not allow government to sit by complacently, happily reporting numbers of vaccine doses administered, when there are still around $80 \%$ of the first target group simply left by the wayside. This group must become a priority if we are not to see more hospitalisations and deaths, both in this wave and in the inevitable fourth wave of the virus.

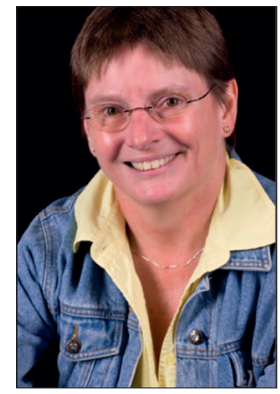

\section{Bridget Farham \\ Editor \\ ugqirha@iafrica.com}

\footnotetext{
1. Alexander K, Xezwi B. Simple but urgent steps needed to end vaccine inequality involving South Africa’s elderly. Daily Maverick, 20 June 2021. https://www.dailymaverick.co.za/article/2021-06-30-simple-buturgent-steps-needed-to-end-vaccine-inequality-in-south-africas-elderly/ (accessed 3 July 2021).

2. Damba-Hendrick N, Steyn D. Villagers forced to make gruelling $79 \mathrm{~km}$ journey to get vaccinated. Daily Maverick, 1 July 2021. https://www.dailymaverick.co.za/article/2021-07-01-villagers-forced-to-makegruelling-70km-journey-to-get-vaccinated/ (accessed 3 July 2021).
}

S Afr Med J 2021;111(8):691. https://doi.org/10.7196/SAMJ.2021.v111i8.15935 